\title{
Oxidative Coupling Reactions with Gold
}

\author{
Hermann A. Wegner*
}

\begin{abstract}
Oxidative coupling reactions are a very powerful tool for the construction of e.g. biaryl compounds, especially because typically no functionalization of the coupling partners is necessary. The use of Au for this transformation is particularly attractive since usually no special precautions to exclude moisture or air are necessary. Furthermore, the combination of oxidative coupling reactions with other Au-catalyzed reactions enables the rapid and efficient construction of molecular complexity, e.g. the constructions of dicoumarins via a domino cyclization oxidative coupling reaction.
\end{abstract}

Keywords: C-C bond formation - Domino/cascade reactions - Gold · Homogeneous catalysis . Oxidative coupling reactions

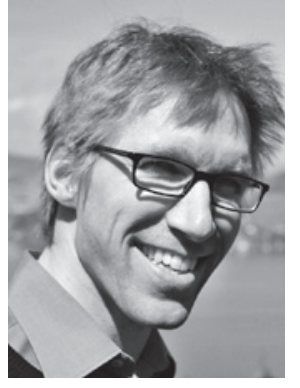

Hermann Wegner studied chemistry at the University of Goettingen, Boston College and Stanford. After completion of his $\mathrm{PhD}$ in 2004 under the supervision of A. de Meijere he moved to the laboratory of J. E. Baldwin for his postdoc, also teaching as a stipendiary lecturer at Merton College, Oxford. In December 2006 he started his Habilitation at the University of Basel as a Liebig fellow.

\section{Introduction}

Gold has always attracted mankind.[1] Since the beginning of recorded history, gold has been used in jewelry, for ornamentation, but also as money and as a store of value. Nowadays it finds additional application in industry, e.g. in electronics or dentistry. Therefore, early on people, known as alchemists, spent tremendous efforts to make gold, and set the stage for modern chemistry. Nowadays, gold is produced by mechanical extraction from rocks. In contrast to other metals it occurs in its genuine form and does not have to be reduced from ore, like iron for example.

Consequently, gold was first thought to be an inert element. However, it turned out to have unique properties in terms of chemical reactivity. First reports using gold as a catalyst in chemical reactions were already published over 30 years ago. ${ }^{[2]}$ But it is only recently that the full potential of gold catalysis has been appreciated. [3] One of the most interesting features is the ability to act as a mild, relatively carbophilic $\pi$-Lewis acid. ${ }^{4]}$ $\pi$-Bonds activated by gold can undergo a variety of reactions such as the addition of nucleophiles, migration of propargyl and other esters, 1,2-migrations, [5] or cycloisomerizations of enynes for example. ${ }^{[6]}$

Redox reactions under homogeneous conditions are less frequently disclosed compared to the vast number of Au-catalyzed reactions. This can be attributed to the high oxidation potential of gold $\left(\varepsilon_{0}\right.$ for $\mathrm{Au} / \mathrm{Au}^{+}=+1.69 \mathrm{~V}$, for $\mathrm{Au} / \mathrm{Au}^{3+}=+1.50 \mathrm{~V}$, for $\left.\mathrm{Au}^{+} / \mathrm{Au}^{3+}=+1.40 \mathrm{~V}\right){ }^{[7]}$ Nevertheless, in the presence of organic substrates three oxidation levels are observed, $\mathrm{Au}(\mathrm{O}), \mathrm{Au}(\mathrm{I})$ and $\mathrm{Au}(\mathrm{III})$. Usually forcing conditions have to be employed to get $\mathrm{Au}(0)$ into a higher oxidation state.

Nevertheless, heterogeneous as well as homogeneous Au-catalyzed redox-type chemistry has been reported. Reductions, especially hydrogenations have been known for decades. ${ }^{[2]}$ Also, a variety of oxidation reactions are known. ${ }^{[2,8]}$ Furthermore, diboration, ${ }^{[9]}$ homo-coupling of boronic acids, ${ }^{[10]}$ cross-coupling reactions ${ }^{[11]}$ and coupling of alkyl triflates with electron-rich arenes ${ }^{[12]}$ have been demonstrated.

\section{Oxidative Coupling Reactions}

The creation of $\mathrm{C}-\mathrm{C}$ bonds is of core importance for the synthesis of organic compounds. The direct connection of two unfunctionalized carbon atoms in a chemoand regioselective way is one of the holy grails in organic chemistry. The traditional way to connect two $\mathrm{C}\left(\mathrm{sp}^{2}\right)-\mathrm{C}\left(\mathrm{sp}^{2}\right)$ centers is by activating at least one of the carbon centers, such as by halogenation, prior to a metal-mediated coupling reaction. ${ }^{[13]}$ The employment of transition metal catalyzed cross coupling reactions is without doubt the most used method to build up this kind of bond. ${ }^{[14]}$ All this reactions suffer from the drawback that the coupling partners have to be functionalized in a suitable manner.

Oxidative coupling of two unfunctionalized aryl compounds is a very convenient way to synthesize a biaryl structure. Lewis acid mediated oxidative coupling of two arene compounds (known as the Scholl reaction) were reported as early as 1912.[15,16] However, usually stoichiometric amounts of Lewis acid are necessary and selectivity and substrate scope are low. Advancements for this transformation using metal catalysts in the presence of an oxidant have been described recently.[17]

\subsection{Oxidative Coupling Reactions Using Stoichiometric Amounts of Au}

With its ability to insert into aromatic $\mathrm{C}-\mathrm{H}$ bonds $\mathrm{Au}$ is a promising candidate to promote oxidative coupling. In fact, theo- 


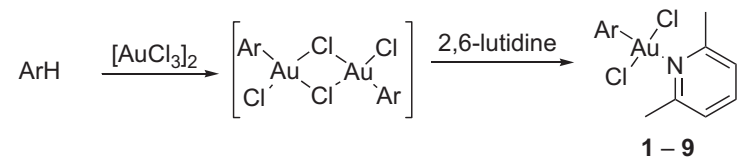

Ar: 1 Ph, 2 4-tolyl, 3 3,4-xylyl, 4 2,4-xylyl, 5 2,5-xylyl, 6 mesityl, 7 4-cumenyl, 8, 4-methoxyphenyl, 9 4-chlorophenyl<smiles>[R]c1ccc([R])c([Al](Cl)(Cl)Cl)c1</smiles>

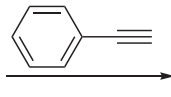$$
1 \mathrm{R}=\mathrm{H} \text {, }
$$
$5 \mathrm{R}=\mathrm{Me}$

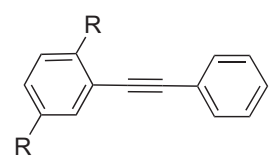

$10 \mathrm{R}=\mathrm{H} \quad 82 \%$ $11 \mathrm{R}=\mathrm{Me} \quad 94 \%$

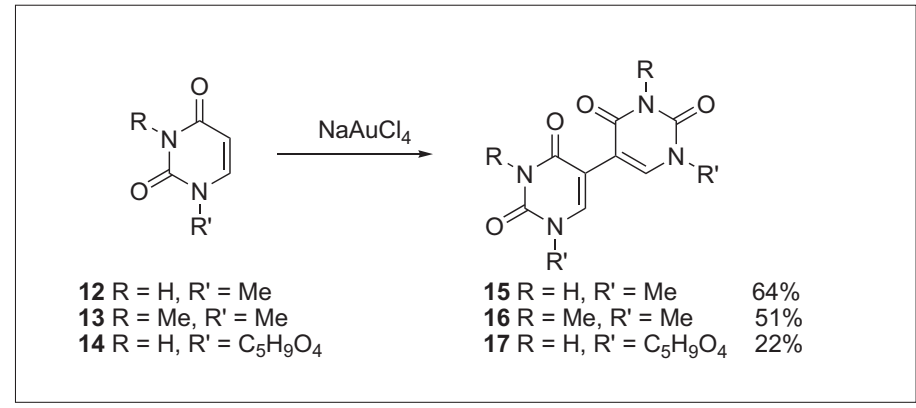

Scheme 1. Oxidative coupling using an aryl $\mathrm{Au}($ III) complex with acetylenes by Fuchita et al.

Scheme 2.

Dimerization of uracil derivatives mediated by $\mathrm{NaAuCl}_{4}$. retical calculations show that the energies of activation for the conversion via disproportionation for both $\mathrm{Au}(\mathrm{I})$ and $\mathrm{Au}(\mathrm{III})$ are rather low. ${ }^{[18]}$ This has been used to convert various $\mathrm{Au}$-complexes ${ }^{[19]}$ to aryl acetylenes by reducing the $\mathrm{Au}(\mathrm{III})$ to the corresponding $\mathrm{Au}(\mathrm{I})$ species (Scheme 1). ${ }^{[20,21]}$ Such aryl complexes can also be prepared via direct $\mathrm{C}-\mathrm{H}$ bond activation with an $\mathrm{Au}(\mathrm{III})$ complex. ${ }^{[22]}$ Attempts to conduct this transformation with catalytic amounts of Au-catalyst failed and gave only the hydroarylation product of the alkyne. [23]

The oxidative coupling of 2-(2'-thienyl)pyridine (Hthpy) ligand on a gold complex was observed by Constable and Sousa by heating $\mathrm{NaAuCl}_{4}$ in the presence of Hthpy. They obtained a complex mixture of products, including Au-complexes of 2-(5' -chloro-2'-thienyl)pyridine and 5,5'-bis(2-pyridyl)-2,2'-bithienyl. [24] Bennett et al. also found the oxidative coupling of ligands in dinuclear $\mathrm{Au}(\mathrm{II})$ complexes.[25]

The dimerization of a nucleobase mediated by stoichiometric amounts of $\mathrm{NaAuCl}_{4}$ was reported by Lippert and coworkers (Scheme 2). ${ }^{[26]}$ He supported the mechanism via $\mathrm{C}-\mathrm{H}$ bond insertion by isolating an $\mathrm{Au}$ complex which is structurally very close to the proposed intermediate by using $\mathrm{K}\left[\mathrm{Au}(\mathrm{CN})_{2} \mathrm{Cl}_{2}\right]$ instead of $\mathrm{NaAuCl}_{4}$. The complex, trans-K[Au(CN) ${ }_{2} \mathrm{Cl}(1,3-$ DimeU $\left.{ }^{-}-\mathrm{C}^{5}\right)$ ] (Fig.) was characterized by ${ }^{1} \mathrm{H}$ NMR spectroscopy as well as X-ray crystallography.[27]

Another interesting oxidative coupling of unfunctionalized aromatics was de- scribed by Osuka and coworkers. ${ }^{[28]}$ They dimerized brominated porphyrines in the presence of $\mathrm{AuCl}_{3}$ and AgOTf. Depending on the equivalents used one or two new bonds are formed (Scheme 3).

Corma and coworkers studied the role of different $\mathrm{Au}$ species in coupling reactions of iodobenzene and phenylacetylene, though in a heterogeneous phase using $\mathrm{Au} / \mathrm{CeO}_{2}$ nanoparticles.[11] Their studies show, that $\mathrm{Au}(0)$ is not active to promote coupling reactions. Au(I) favors the Sonogashira reaction in contrast to $\mathrm{Au}(\mathrm{III})$ which promotes homocoupling of the acetylene as well as iodobenzene.

An interesting sideproduct has been reported by Hashmi et al. while exploring the cyclization of tertiary allenyl carbinols.[29] Besides the desired dihydrofurane 23, 24 and 25 were isolated (Scheme 4). The authors propose the mechanism in Scheme 5 to explain the outcome of the reaction. The main product originates from coordination of the $\mathrm{Au}(\mathrm{III})$ catalyst to the remote double bond, followed by cyclization to $\mathbf{B}$ and deprotonation to $\mathbf{C}$ to yield the dihydrofurane after proto-demetallation. The intermediate $\mathbf{C}$, however, can also promote a second cyclization to the dimeric species $\mathbf{D}$, which will eventually lead to the dimer by reductive elimination. Another possibility for the formation of $\mathbf{D}$ could be via ligand exchange reaction. The mechanism is in agreement with a maxi-

$$
{ }_{\mathrm{Cl}}^{\mathrm{Cl}} \mathrm{CH}_{\mathrm{CN}}^{\mathrm{O}}
$$

Fig. trans- $\mathrm{K}\left[\mathrm{Au}(\mathrm{CN})_{2} \mathrm{Cl}\left(1,3-\mathrm{DimeU}^{-}-\mathrm{C}^{5}\right)\right]$.

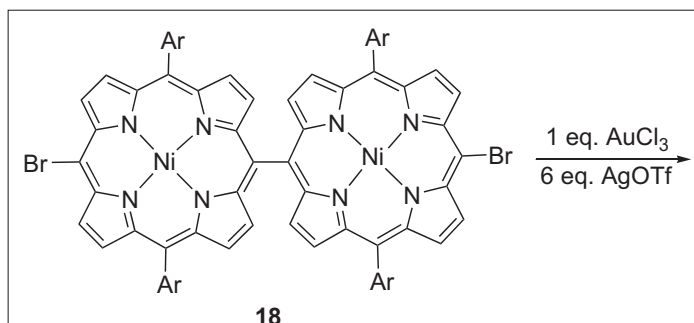

18

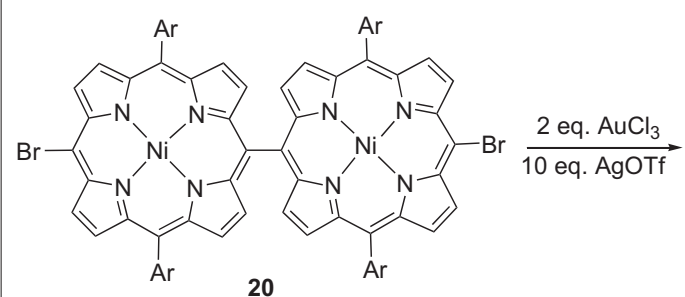

20

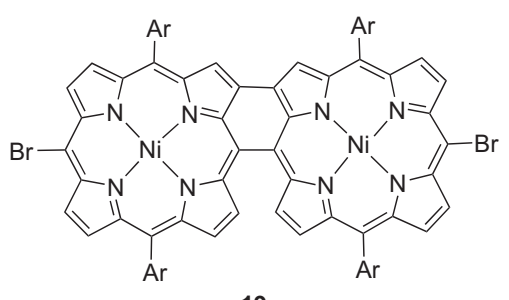

19
$86 \%$

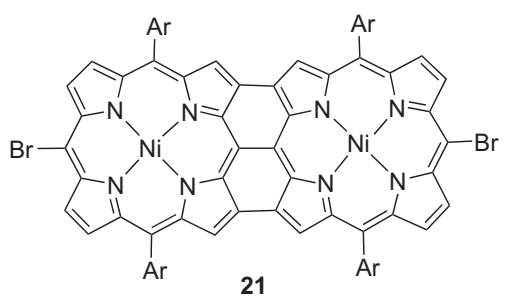

$83-91 \%$

Scheme 3. Dimerization of porphyrin derivatives mediated by $\mathrm{AuCl}_{3}$.
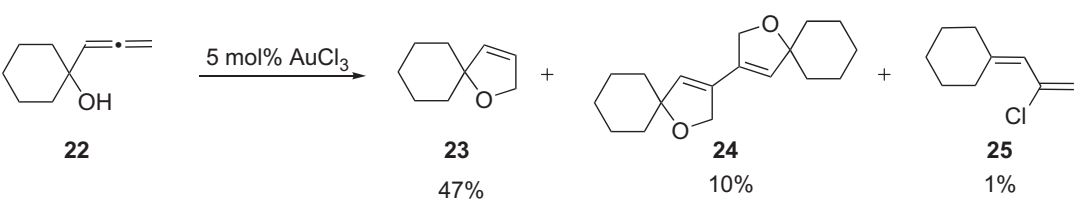

Scheme 4. Formation of a side product due to an $\mathrm{Au}(\mathrm{III})$-mediated oxidative coupling reaction. 


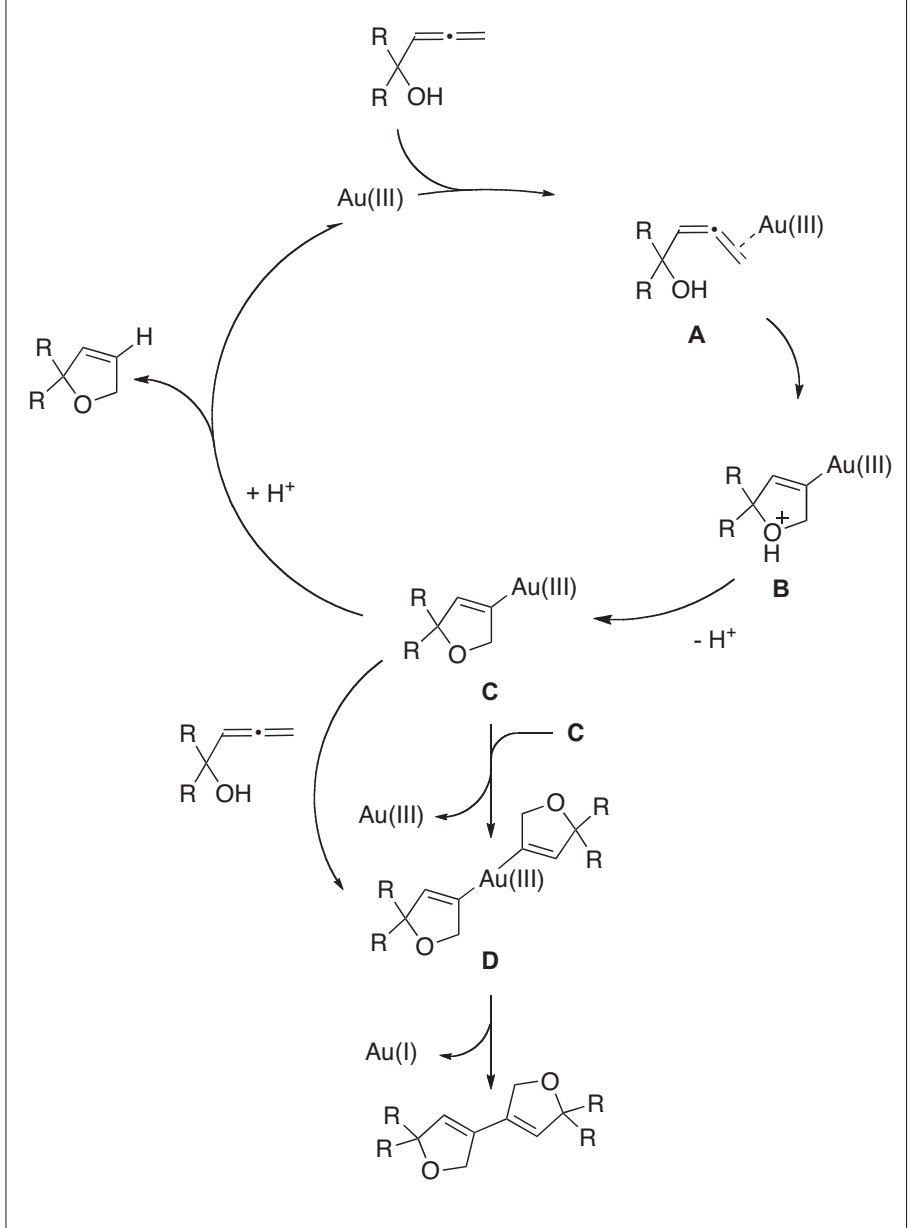

Scheme 5. Possible mechanism for the formation of the main and the side product in the $\mathrm{Au}(\mathrm{III})$ catalyzed reaction. mum yield of the dimer, which is twice the amount of the $\mathrm{Au}(\mathrm{III})$ catalyst.

\subsection{Oxidative Coupling Reactions Using Catalytic Amounts of Au}

The examples above show clearly the potential of $\mathrm{Au}$ for oxidative coupling reactions. Nevertheless, it would be highly desirable to use the precious $\mathrm{Au}$ only in catalytic amounts and employ a cheap oxidant to regenerate the catalytic active $\mathrm{Au}(\mathrm{III})$ species.

The first example using only catalytic amounts of $\mathrm{Au}$ for an oxidative coupling of arenes to form biaryl compounds was reported by a research team led by Tse from Rostock, Germany (Scheme 6). ${ }^{[30]}$ The catalyst of choice is $\mathrm{HAuCl}_{4}$ combined $\mathrm{AuCl}\left(\mathrm{PPh}_{3}\right)$ showed similar reactivity. Other oxidants, such as $\mathrm{K}_{2} \mathrm{~S}_{2} \mathrm{O}_{8}$, Oxone ${ }^{\circledR}$, $25 \% \mathrm{CH}_{3} \mathrm{CO}_{3} \mathrm{H}, \mathrm{Cu}(\mathrm{OAc})_{2}$ or $45 \%$ 2-iodoxybenzoic acid (IBX), showed inferior results. Lewis acids, which are usually employed in this kind of transformation, e.g. $\mathrm{FeCl}_{3}$ and $\mathrm{BF}_{3} * \mathrm{OEt}_{2}$, did not furnish the biphenyl compounds under these catalytic conditions. Notably, no special precautions like exclusion of water or air have to be taken. with $\mathrm{PhI}(\mathrm{OAc})$, as the oxidant, although
The reaction tolerates a variety of substituents. Alkyl, OMe, ester, as well as nitro groups can be present. Additionally, all halogens, even iodines, which have the weakest aryl bond, survive the coupling conditions. The regioselectivity follows the rules for aromatic substitution. Therefore, the authors exclude a free radical mechanism.

Recently, in our group we developed a domino cyclization oxidative coupling reaction of alkynylarylesters to dicoumarins using catalytic amounts of $\mathrm{Au}$ (Scheme 7). ${ }^{[31,32]}$ Originally we isolated the dimer 31 only in trace amounts as a side product. Running the reaction with stoichiometric amounts of Au-catalyst gave the dimer $\mathbf{3 1}$

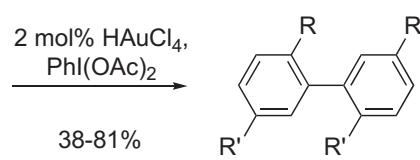

27

$\mathrm{R}=\mathrm{Me}, \mathrm{F}, \mathrm{Cl}, \mathrm{Br}, \mathrm{NO}_{2}$

$\mathrm{R}^{\prime}=\mathrm{Me}, t \mathrm{Bu}, \mathrm{OMe}$,

$\mathrm{CO}_{2} \mathrm{Me}$

$2 \mathrm{~mol}^{2} \mathrm{HAuCl}_{4}$,

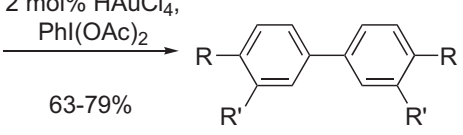

29

$\mathrm{R}=\mathrm{F}, \mathrm{I}, \mathrm{CO}_{2} \mathrm{Me}$

$\mathrm{R}^{\prime}=\mathrm{OMe}$
Scheme 6. Au-catalyzed oxidative coupling reaction for the synthesis of biaryl compounds.

as the main product. After screening a variety of conditions the use of $\mathrm{HAuCl}_{4}$ in 1,2-dichloroethane (DCE) and $t$ - $\mathrm{BuOOH}$ as an oxidant we were able to regenerate the $\mathrm{Au}(\mathrm{III})$ species, necessary for the oxidative coupling to occur, and to obtain the dimer 31 as the main component, even with catalytic amounts of catalyst as low as $1 \mathrm{~mol} \%$.

As in the case of the oxidative coupling of Tse and coworkers a variety of substituents are tolerated. Alkyl, aryl as well as alkoxy groups are accepted. Even a methyl substituent on the alkyne portion did not inhibit dimerization. Unfortunately, substrates bearing electron-withdrawing substituents on the aryl portion did not give any dimeric or even monomeric coumarin. Worth mentioning is the high regioselectivity: Using the original protocol for the coumarin cyclization a mixture of two isomers is obtained for 3-methoxyphenyl propiolate. ${ }^{[33]}$ Whereas for the domino cyclization oxidative coupling reaction only the shown isomers $\mathbf{3 6}$ and $\mathbf{3 4}$ are observed (Scheme 8).

To get more details on the mechanism both parts of the reaction were studied individually. Deuteration in ortho-position to the ester functionality should reveal whether the reaction proceeds via an insertion in the $\mathrm{C}-\mathrm{H}$ bond or via a Friedel Crafts-type mechanism. The result showed a 1:1 ratio of insertion into the $\mathrm{C}-\mathrm{H}$ and the $\mathrm{C}-\mathrm{D}$ bond pointing to the latter (Scheme 9).

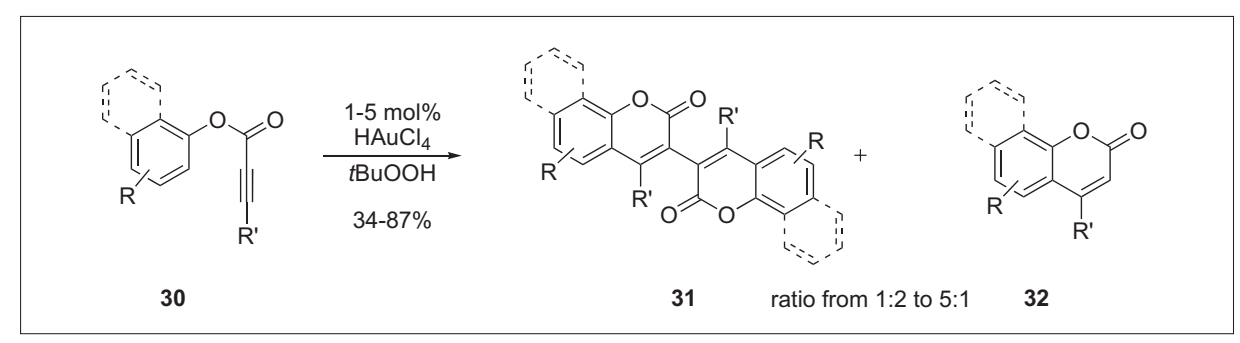

Scheme 7. Domino cyclization oxidative coupling reaction for the formation of dicoumarins $(R=$ $\left.\mathrm{H}, \mathrm{Me}, \mathrm{BBu}, \mathrm{Ph}, \mathrm{OMe}, \mathrm{OCH}_{2} \mathrm{O}, \mathrm{OBn} ; \mathrm{R}^{\prime}=\mathrm{H}, \mathrm{Me}\right)$. 


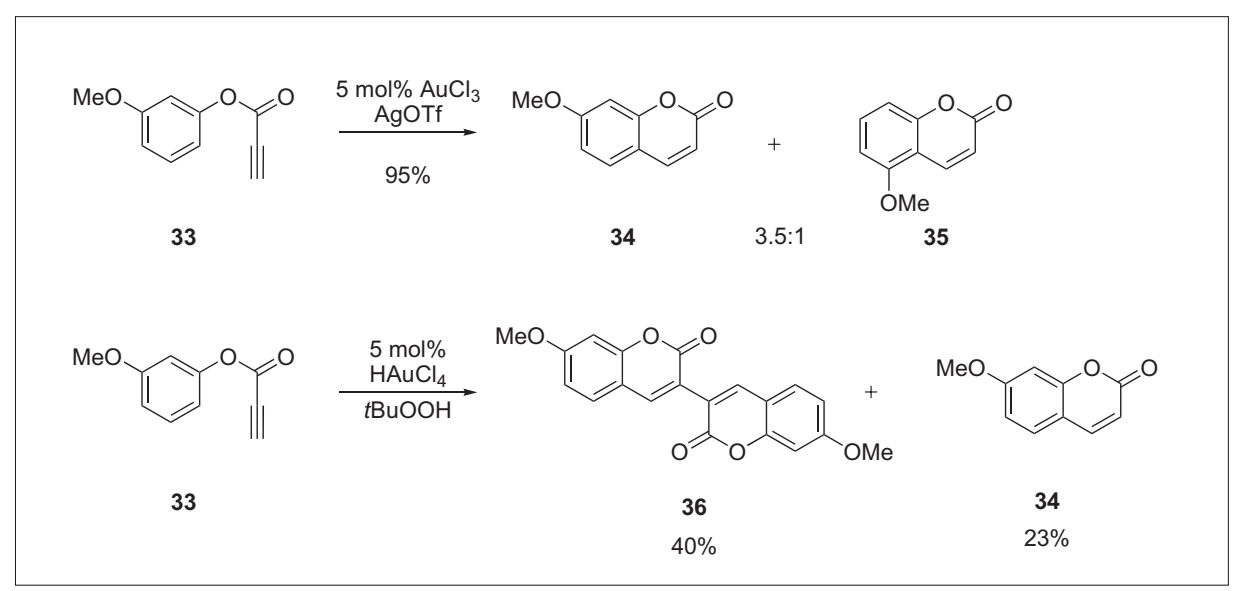

Scheme 8. Regioselectivity for the cyclization with the condition of Shi and $\mathrm{He}$ (top) and in the domino cyclization oxidative coupling reaction (bottom).

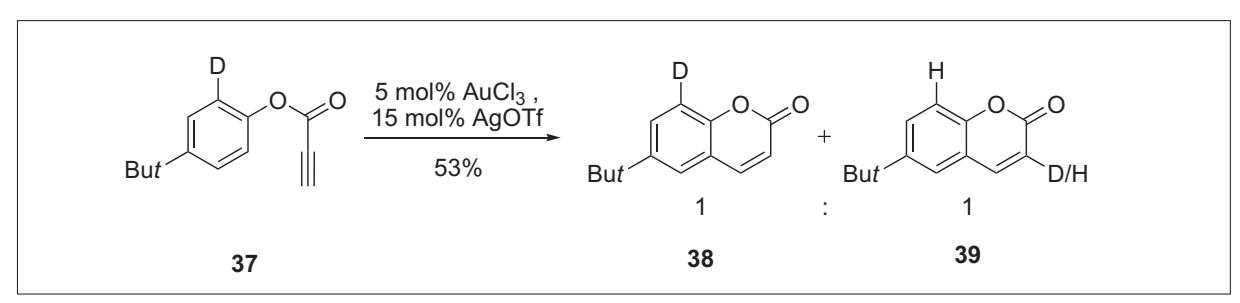

Scheme 9. Deuteration experiment to elucidate the mechanism of the first part of the reaction.

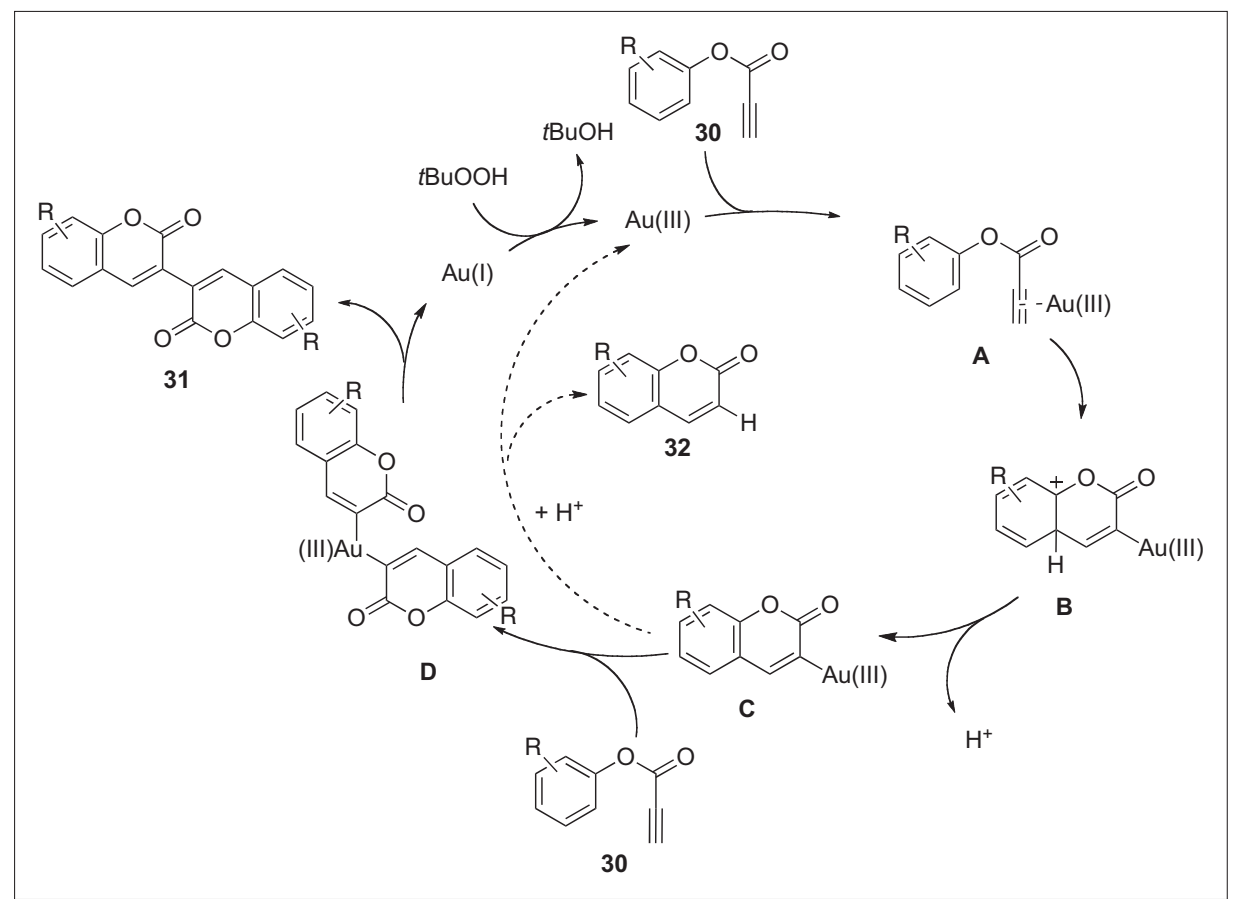

Scheme 10. Proposed mechanism for the domino cyclization oxidative coupling reaction.

For the oxidative coupling two pathways are conceivable: First, the Aucomplex $\mathbf{C}$ (Scheme 10) undergoes a dimerization after the cyclization. Second, the Au-catalyst performs an insertion into the $\mathrm{C}-\mathrm{H}$ bond of a monomeric coumarin 32 and does then the oxidative coupling similar to the reaction of Tse and coworkers.

However, submission of the monomeric coumarin $\mathbf{3 2}$ to the conditions of the domino cyclization oxidative coupling reaction did not give the dimeric species $\mathbf{3 1}$, ruling out a pathway via insertion into the monocoumarin 32.

Putting the pieces together the following catalytic cyclic is put forward: After coordination and cyclization the intermediate $\mathbf{C}$ is formed. Protonation furnishes the monocoumarin 32. Cyclization of a second molecule of starting material or ligand exchange leads to complex $\mathbf{D}$, which will yield the dimeric product $\mathbf{3 1}$ after reductive elimination. Now the resulting $\mathrm{Au}(\mathrm{I})$ species is efficiently oxidized by $t$ - $\mathrm{BuOOH}$ to reinstate the necessary $\mathrm{Au}(\mathrm{III})$ species to close the catalytic cycle (Scheme 10).

The dicoumarins are interesting candidates as UV-absorbers as well as laser dyes. In these dicoumarins the usual decomposition mechanism for monomeric coumarins via dimerization under irradiation is blocked resulting in a higher photostability.

\section{Concluding Remarks}

In summary, $\mathrm{Au}$ is able to mediate oxidative coupling reactions. Especially catalytic conditions are attractive for an efficient synthesis of biaryl compounds, which has been shown by Tse and coworkers and our group. The combination of this reactivity of Au with other features in domino reactions promises an economic entry into molecular complexity, e.g. dicoumarins via a domino cyclization oxidative coupling reaction.

\section{Addendum}

Very recently Pale and coworkers observed a similar dimerization as Hashmi et al. with stoichiometric amounts of Au: when treating $\omega$-acetylnic acids with $\mathrm{AlCl}_{3}$, lactone dimers could be isolated. ${ }^{[34]}$

\section{Acknowledgements}

I wish to thank the editorial board of CHIMIA for initiating this special issue and for giving me the opportunity to contribute.

Received: January 9, 2009

[1] B. Larmer, National Geographic 2009, 34.

[2] a) G. C. Bond, Gold Bull. 1972, 5, 11; b) L.-U. Meyer, A. de Meijere, Tetrahedron Lett. 1976, 17, 497.

[3] a) G. Dyker, Angew. Chem. Int. Ed. 2000, 39 4237; b) N. Krause, A. Hoffmann-Röder, Org. Biomol. Chem 2005, 3, 387; c) A. S. K. Hashmi, Angew. Chem. Int. Ed. 2005, 44, 6990; d) L. M. Zhang, J. W. Sun, S. A. Kozmin, Adv. Synth. Catal. 2006, 348, 2271; e) R. A. Widenhoefer, X. Han, Eur. J. Org. Chem. 2006, 4555; f) A. S. K. Hashmi, G. J. Hutchings, Angew. Chem., Int. Ed. 2006, 45, 7896; g) D. J. Gorin, F. D. Toste, Nature 2007, 446, 395; h) E. Jiménez-Núñez, A. M. Echavarren, Chem. Commun. 2007, 333; i) A. S. K. Hashmi, Chem. Rev. 2007, 107, 3180; j) Z. Li, C. Brouwer, C. He, Chem. Rev. 2008, 108, 3239; k) A. Arcadi, Chem. Rev. 2008 . $108,3266 ; 1)$ For a review on enantioselective $\mathrm{Au}(\mathrm{I})$ catalysis, see: R. A. Widenhoefer, Chem. Eur. J. 2008, 14, 5382; m) For a review on Aucatalyzed cascade reactions, see: S. F. Kirsch, Synthesis 2008, 3183.

[4] A. Fürstner, P. W. Davies, Angew. Chem., Int. Ed. 2007, 46, 3410.

[5] B. Crone, S. F. Kirsch, Chem. Eur. J. 2008, 14 3514.

[6] E. Jiménez-Núñez, A. M. Echavarran, Chem. Rev. 2008, 108, 3326. 
[7] 'Lehrbuch der Anorganischen Chemie' A. F. Holleman, E. Wiberg, Walter de Gruyter, Berlin 1995, 101. Auflage, p. 1353.

[8] a) B. Guan, D. Xing, G. Cai, X. Wan, N. Yu, Z. Fang, L. Yang, Z. Shi, J. Am. Chem. Soc. 2005 , 127, 18004; b) D. E. De Vos, B. F. Sels, Angew. Chem., Int. Ed. 2005, 44, 30 and references therein.

[9] a) R. Corberán, J. Ramírez, M. Poyatos, E. Peris, E. Fernández, Tetrahedron: Asymmetry 2006, 17, 1759; b) R. T. Baker, P. Nguyen, T. B. Marder, S. A. Westcott, Angew. Chem. Int. Ed. Engl. 1995, 34, 1336.

[10] C. González-Arellano, A. Corma, M. Iglesias, F. Sánchez, Chem. Commun. 2005, 1990.

[11] a) C. González-Arellano, A. Abad, A. Corma, H. García, M. Iglesias, F. Sánchez, Angew. Chem., Int. Ed. 2007, 46, 1536.

[12] Z. Shi, C. He, J. Am. Chem. Soc. 2004, 126, 13596.

[13] J. Hassan, M. Sévignon, C. Gozzi, E. Schulz, M. Lemaire, Chem. Rev. 2002, 102, 1359.

[14] a) 'Metal-Catalyzed Cross-Coupling Reactions', Ed. A. de Meijere, F. Diederich, Wiley-VCH, Weinheim, 2nd ed, 2004; vol. 1-2; b) A. Roglans, A. Pla-Quintana, M. Moreno-Manas, Chem. Rev. 2006, 106, 4622 and references therein.

[15] a) R. Scholl, C. Seer, Liebigs Ann. 1912, 394 111; b) B. T. King, J. Kroulík, C. R. Robertson, P. Rempala, C. L. Hilton, J. D. Korinek, L. M. Gortari, J. Org. Chem. 2007, 72, 2279.

[16] For reviews see: a) S. R. Waldvogel, D. Mirk, in 'Handbook of C-H Transformations', Ed. G. Dyker, Wiley-VCH, Weinheim, 2005, vol. 1, pp. 251; b) G. Lessene, K. S. Feldman, in 'Modern Arene Chemistry', Ed. D. Astruc, Wiley$\mathrm{VCH}$, Weinheim, 2002, pp. 479 and references therein.

[17] a) T. A. Dwight, N. R. Rue, D. Charyk, R. Josselyn, B. DeBoef, Org. Lett. 2007, 9, 3137; b) D. R. Stuart, K. Fagnou, Science 2007, 316, 1172; c) Y. Rong, R.-S. Li, W.-J. Lu, Organometallics 2007, 26, 4376; d) K. Masui, H. Ikegami, A. Mori, J. Am. Chem. Soc. 2004 126, 5074; e) B. Kramer, S. R. Waldvogel, Angew. Chem., Int. Ed. 2004, 43, 2446; f) A V. Iretskii, S. C. Sherman, M. G. White, J. C. Kenvin, D. A. Schiraldi, J. Catal. 2000, 193, 49; g) A. Shiotani, H. Itatni, T. Inagaki, J. Mol. Catal. 1986, 34, 57.
[18] a) C. J. Jones, D. Taube, R. A. Periana, Angew. Chem., Int. Ed. 2004, 43, 4626; b) B. F. Straub, Chem. Commun. 2004, 1726.

[19] a) J. Vicente, M.-D. Bermúdez, M.-T. Chicote, M.-J. Sánchez-Santano, J. Organomet. Chem. 1990, 381, 285; b) J. Vicente, A. Arcas, M. Mora, X. Solans, M. Font-Altaba, J. Organomet. Chem. 1986, 309, 396; c) J. Vicente, A. Arcas, M. T. Chicote, J. Organomet. Chem. 1983, 252, 251 and references therein.

[20] O. Schuster, H. Schmidbaur, Inorg. Chim. Acta 2006, 359, 3769.

[21] Y. Fuchita, Y. Utsunomiya, M. Yasutake, $J$. Chem. Soc., Dalton Trans. 2001, 2330.

[22] a) P. W. J. de Graaf, J. Boersma, G. J. M. van der Kerk, J. Organomet. Chem. 1976, 105, 399; b) K. S. Liddle, C. Parkin, J. Chem. Soc., Chem. Commun. 1972, 26; c) M. S. Kharasch, H. S. Isbell, J. Am. Chem. Soc. 1931, 53, 3053.

[23] M. T. Reetz, K. Sommer, Eur. J. Org. Chem. 2003, 3485.

[24] E. C. Constable, L. R. Sousa, J. Organomet. Chem. 1992, 427, 125 .

[25] M. A. Bennett, D. C. R. Hockless, A. D. Rae, L. L. Welling, A C. Willis, Organometallics 2001, 20, 79.

[26] F. Zamora, P. Amo-Ochoa, B. Fischer, A. Schimanski, B. Lippert, Angew. Chem., Int. Ed. 1999, 38, 2274.

[27] F. Zamora, E. Zangrando, M. Furlan, L. Randaccio, B. Lippert, J. Organomet. Chem. 1998, 552, 127.

[28] A. K. Sahoo, Y. Nakamura, N. Aratani, K. S. Kim, S. B. Noh, H. Shinokubo, D. Kim, A. Osuka, Org. Lett. 2006, 8, 4141.

[29] A. S. K. Hashmi, M. C. Blanco, D. Fischer, J. W. Bats, Eur. J. Org. Chem. 2006, 1387.

[30] A. Kar, N. Mangu, H. M. Kaiser, M. Beller, M. K. Tse, Chem. Commun. 2008, 386.

[31] H. A. Wegner, S. Ahles, M. Neuenburg, Chem. Eur. J. 2008, 14, 11310.

[32] L. F. Tietze, G. Brasche, K. M. Gericke, 'Domino Reactions in Organic Synthesis', Wiley-VCH, Weinheim, 2006.

[33] Z. Shi, C. He, J. Org. Chem. 2004, 69, 3669.

[34] H. Harkat, A. Demelé, J.-M. Weibel, A. Blanc, P. Pale, Tetrahedron 2009, doi: 10.1016/j. tet.2008.10.112. 